\title{
Análise quantitativa de planta alimentícia não-convencional e plantas medicinais, comercialização e utilização de agrotóxicos em canteiros pertencentes ao projeto "Hortas Comunitárias” de Birigui (São Paulo)
}

\author{
Isabela Contel Poletti ${ }^{1}$, Ana Paula Freitas da Silva Rodrigues ${ }^{2}$, Beatriz Silva Dourado ${ }^{3}$ e \\ Drielly Rodrigues Viudes ${ }^{4}$
}

O cultivo alimentar em meio urbano é considerado um meio de resgate da soberania alimentar, sendo promovido em Birigui (SP) pelo projeto "Hortas Comunitárias". Objetivou-se realizar um levantamento sobre a presença de PANC (planta alimentícia não convencional), plantas medicinais, agrotóxicos e comercialização dos produtos, bem como comparar com o previsto na legislação municipal. Realizou-se análise quantitativa em $50 \%$ das hortas. Constatou-se presença significativa de PANC (39 espécies) e plantas medicinais (44 espécies), com maior frequência da Erva-de-santa-maria e Capim-limão. A comercialização se fez presente em 6,7\% e o uso de agrotóxicos em 44\%. Com os dados deste trabalho ações de intervenção podem ser traçadas para adequação à legislação municipal, estímulo ao consumo das plantas presentes nas hortas, e educação sobre malefícios do agrotóxico visando promoção de saúde.

Palavras-chave: Agrotóxico, extensão comunitária, plantas medicinais, Segurança Alimentar e Nutricional.

\section{Quantitative analysis of unconventional food plant and medicinal plants, commercialization and use of agrochemicals in beds belonging to the project "Community Gardens" of Birigui (São Paulo)}

Food cultivation in urban areas is considered a means of rescuing food sovereignty, being promoted in Birigui (SP) by the project "Community gardens". The objective was to carry out a survey on the presence of PANC (unconventional food plant), medicinal plants, pesticides and commercialization of the products, as well as to

${ }^{1}$ Nutricionista, graduada pelo Centro Universitário Católico Salesiano Auxilium de Araçatuba - SP. Endereço para correspondência: Rua Capitão José Cordeiro no 559 - Silvares - Birigui - SP. CEP: 16.201-012. E-mail. isabelacontel96sale@hotmail.com

${ }^{2}$ Nutricionista, graduada pelo Centro Universitário Católico Salesiano Auxilium de Araçatuba - SP. Endereço para correspondência: Rua Newton Prado no 201 - São Joaquim - Araçatuba - SP. CEP: $16050-$ 425. E-mail: anny.freitas.r@hotmail.com

3Nutricionista, graduada pelo Centro Universitário Católico Salesiano Auxilium de Araçatuba - SP. Endereço para correspondência: Rua 21 de abril no 232 - Vila Xavier - Birigui - SP. CEP: 16203-008. E-mail. 3Nutricionista, graduada pelo Centro Universitário Católico Salesiano Auxilium de Araçatuba - SP. Endereço para correspondência: Rua 21 de abril no 232 - Vila Xavier - Birigui - SP. CEP: 16203-008. E-mail.
bia_benassidourado@hotmail.com bia_benassidourado@hotmail.com

${ }^{4}$ Nutricionista da Prefeitura Municipal de Birigui (SP). Mestre em Ciências da Saúde pela Universidade Federal de São Paulo (UNIFESP). Endereço para correspondência: Rua Santos Dumont no 146 - Centro - Birigui - SP. CEP:16200-095.E-mail. driviudes@gmail.com 
compare with the provisions of municipal legislation. Quantitative analysis was performed in $50 \%$ of the gardens. It was observed a significant presence of PANC (39 species) and medicinal plants (44 species), with higher frequency of Santa-Maria and Lemon- grass herbs. Commercialization was present in $6.7 \%$ and the use of agrochemicals in $44 \%$. With the data of this work, intervention actions can be traced to suit the municipal legislation, stimulus to the consumption of plants present in the gardens, and education about the harmful effects of the agrotoxic aiming health promotion.

Keywords: Agrochemicals, community-institutional relations, medicinal plants, Food and Nutrition Security.

\section{INTRODUÇÃO E OBJETIVOS}

O cultivo de alimentos em meio urbano é uma prática realizada há muitos anos. A agricultura urbana e periurbana (AUP) adquiriram destaque na segunda metade da década de 1990 auxiliando nos processos de desenvolvimento sustentável das pessoas e sendo uma estratégia de sobrevivência das populações mais pobres ${ }^{[1,2]}$.

Por conceito inclui produção, prestação de serviço e transformação, de forma segura, gerando produtos agrícolas de várias espécies e pecuários direcionados ao autoconsumo, doações, trocas, aproveitando-se de forma sustentável o solo, água, resíduos sólidos, mão de obra, entre outros ${ }^{[3]}$.

Dentre a ampla variedade de hortaliças comuns cultivadas nas hortas urbanas, ressalta-se a planta alimentícia não convencional (PANC), ou seja, plantas comestíveis, regionais e de fácil manejo, muitas vezes espontâneas como uma alternativa alimentar e uma opção de resgate da soberania alimentar, cultural e uma excelente maneira de agregar diversidade alimentar (nutrientes e fitoquímicos) e que, muitas vezes, são desconhecidas pela população. Entretanto, a falta de informações por parte da população quanto a suas grandes propriedades nutricionais e/ou medicinais, e modo de preparo faz com que seu consumo seja reduzido. A maioria das PANC são bem adaptáveis, nascendo em meio a hortas abandonadas, quintais e calçadas ${ }^{[4,5]}$.

O fácil acesso às hortas comunitárias urbanas permite que muitas famílias de baixa renda tenham acesso a alimentos naturaise sem custo. Deve-se, ainda, considerar que essas plantas possuem um alto valor nutritivo, que podem complementar de forma eficaz a alimentação da população, diversificar cardápios, além do baixo custo e poder servir de fonte de renda por meio de seus subprodutos como: comercialização de geleias, farinhas, entre outros. Neste cenário surge a importância da identificação e localização desses alimentos na cidade, para viabilizar a indicação segura para o consumo pela população[ ${ }^{[]}$.

Com o intuito de melhorar a qualidade de vida e alimentar dos munícipes, a Prefeitura Municipal de Birigui (SP) junto à Secretaria de Assistência e Desenvolvimento Social criou um programa de produção de alimentos denominado "Hortas Comunitárias", em que foram implantadas na cidade, desde 1994 até o presente momento, cerca de 60 hortas comunitárias, atendendo a toda população em situação de vulnerabilidade. A prefeitura subsidia o local, algumas sementes e/ou mudas, água necessária para manter a produção dos vegetais e adubação de acordo com a disponibilidade; é ainda, responsável pela fiscalização e distribuição dos canteiros ${ }^{[6]}$.

Devido ao grande potencial e alcance municipal do projeto, objetivou-se identificar quais hortas comunitárias possuem PANC e plantas medicinais, e se no cultivo havia utilização de resíduos químicos, bem como prática de comercialização e comparar com a proposta oficial de execução do projeto para que intervenções possam ser aplicadas, se necessário, pelos responsáveis.

\section{MATERIAL E MÉTODOS}

O projeto foi apresentado às Secretarias responsáveis que autorizaram a realização da pesquisa, visto o grande interesse por parte do município. A critério da Secretaria de Assistência e Desenvolvimento Social de Birigui foram designadas 30 hortas para visitação. 
De acordo com os endereços fornecidos elaborou-se um cronograma de visitas. Foram coletados dados de todos os canteiros pertencentes a cada horta, e relacionadas às quantidades, variedades de PANC e plantas medicinais, bem como a presença de comercialização e uso de agrotóxicos nestas hortas. Todas as informações foram descritas em um formulário impresso elaborado pelas pesquisadoras.

A identificação das plantas foi realizada com a ajuda dos horticultores presentes nas hortas no momento da visita, através de uma conversa informal, e para confirmação fotos das plantas foram comparadas as constantes no livro "Plantas alimentícias não convencionais (PANC) no Brasil'"[4] com ajuda de especialista da área e conhecedor das hortas visitadas.Após a coleta de dados, os mesmos foram compilados numa planilha do software Microsoft Exce ${ }^{\mathbb{B}}$ para análise descritiva dos dados.

Ao fim da pesquisaos achados foram encaminhados para a Secretaria de Meio Ambiente e Serviço Social de Birigui (SP) para que tomassem conhecimento da realidade do projeto, e a partir disso formular estratégias de intervenção visando à segurança alimentar e nutricional das famílias atendidas e regular execução do projeto.

\section{RESULTADOS E DISCUSSÃO}

Foram realizadas visitas a 30 hortas comunitárias de Birigui - SP nos meses de junho e julho, nos horários em que há maior fluxo de horticultores nas hortas, sendo entre $6 \mathrm{~h} 30$ e $9 \mathrm{~h} 00 \mathrm{da}$ manhã e no período da tarde, entre $17 \mathrm{~h}$ e $18 \mathrm{~h}$, representando $50 \%$ das hortas existentes na cidade.

De acordo com a catalogação das PANC, constante na Tabela 1, pode-se constatar que a Ervade-santa-maria (ChenopodiumambrosioidesL.) e o Capimlimão (Cymbopogoncitratus (DC.) Stapf) estavam presentes em 28 e 29 hortas respectivamente, fator que pode ser explicado pela fácil propagação e o conhecimento popular sobre elas ser comum e bem disseminado. O Trevinho (Oxalislatifólia Kunth) também foi muito encontrado nas hortas.
Dentre as plantas medicinais encontradas, pode-se perceber a grande quantidade de Arruda (Rutagraveolens) presente em 25 hortas, Alecrim (Rosmarinusofficinalis) em 24, e Hortelã verde (Menthaspicata) em 22 hortas, Erva-de-santa-maria (Chenopodiumambrosioides L.) em 29 hortas e o Capimlimão (Cymbopogoncitratus (DC.) Stapf) (28 hortas). Os dados estão detalhados na Tabela 2.

Durante a visita, foi possível observar a comercialização das hortaliças cultivadas em mais de $60 \%$ das hortas, sendo de alta comercialização em $6,7 \%$. Pode-se considerar que há no geral baixa comercialização porque as vendas ocorrem com a cobrança de valores simbólicos, apenas para moradores da região, com o intuito de recuperar o valor gasto com a manutenção dos canteiros quando o suporte municipal não é suficiente. Destaca-se que em $33 \%(n=10)$ das hortas não se realiza nenhum tipo de comercialização, isto é, tudo o que é plantado é para consumo familiar, podendo ser realizadas apenas doações para familiares, amigos ou instituições da cidade, segundo informações do responsável das hortas e observação durante visita. 
PANC e plantas medicinais no projeto Hortas Comunitárias. Poletti et al.

Tabela 1. PANCs encontradas nas hortas comunitárias e suas quantidades em canteiros, hortas, e fora dos canteiros

\begin{tabular}{|c|c|c|c|c|}
\hline Nome popular & Nome científico & $\begin{array}{l}\text { Canteiros } \\
\text { (n) }\end{array}$ & $\begin{array}{c}\text { Hortas } \\
\text { (n) }\end{array}$ & $\begin{array}{l}\text { Fora dos } \\
\text { canteiros } \\
\text { (n) }\end{array}$ \\
\hline Açafrão da Terra/Cúrcuma & Curcuma longa $\mathrm{L}$. & 30 & 12 & $I^{*}$ \\
\hline Alfavaca & Ocimum capecbianum $\mathrm{Mill}$ & 14 & 5 & 1 \\
\hline Almeirão Roxo & Lactuca canadensesL. & 44 & 9 & 0 \\
\hline Arnica/Couvinha & Porophyllum ruderale(Jacq.) Cass. & 11 & 6 & $\mathrm{I}^{*}$ \\
\hline Azedinha/Trevinho & Oxalis latifóliaKunth & 127 & 19 & $I^{*}$ \\
\hline Beijo-turco/Maria-sem-vergonha & Impatiens wallerianaHook. $\mathrm{f}$. & 26 & 7 & 0 \\
\hline Beldroega & Portulaca oleracea $\mathrm{L}$. & 8 & 3 & 2 \\
\hline Bredo/Caruru & Amarantbus deflexusL. & 16 & 4 & 0 \\
\hline Capim Limão/Erva Cidreira & Cymbopogon citratus(DC.) Stapf & 64 & 28 & 36 \\
\hline Capuchinha & Tropaeolum majusL. & 0 & 1 & $I^{*}$ \\
\hline Carqueja & Baccharis trimera & 22 & 11 & 0 \\
\hline Cártamo & Carthamus tinctoriusL. & 1 & 1 & 0 \\
\hline Caruru Amargo & Erecbtites hieraciïfolius(L.) Raf. Ex DC. & 5 & 5 & $I^{*}$ \\
\hline Chicória-de-caboclo & Eryngium foetidumL. & 2 & 1 & 0 \\
\hline Chuchu & Secbium edule(Jacq.) Sw. & 2 & 2 & 0 \\
\hline Coentrão & Enygium coronatumHook. \& Arn. & 21 & 11 & 0 \\
\hline Dália & Dablia pinnataCav. & 4 & 3 & 0 \\
\hline Dente de leão & Taraxacum officinale F.H. Wigg. & 6 & 4 & 2 \\
\hline Erva-de-Santa-Maria/Mastruz & Chenopodium ambrosioidesL. & 98 & 29 & 24 \\
\hline Fisális & Physalis pubescensL. & 1 & 1 & 0 \\
\hline Funcho/ Falsa-erva-doce & Foeniculum vulgareMill. & 9 & 6 & $I^{*}$ \\
\hline Hibisco & Hibiscus sabdariffa $\mathrm{L}$. & 2 & 2 & 0 \\
\hline Hortelã Pimenta & Plectrantbus amboinicus(Lour.) Spreng. & 9 & 5 & 0 \\
\hline Inhame chinês & Colocasia esculenta (L.) Schott & 17 & 4 & $\mathrm{I}^{*}$ \\
\hline Melão-de-São-Caetano & Momordica charantiaL. "Goya" & 2 & 2 & 0 \\
\hline Mentruz & Coronopus didymus(L.) Sm. & 15 & 7 & 6 \\
\hline Mostarda & Brassica juncea (L.) Czern. & 16 & 7 & 0 \\
\hline Noni & Morinda citrifolia $\mathrm{L}$. & 5 & 6 & 1 \\
\hline Ora-pro-nobis & Pareskia aculeata Mill. & 0 & 1 & 6 \\
\hline Palma & Opuntia ficus-indica(L.) Mill. & 1 & 1 & 0 \\
\hline Pinheiro & Araucaria angustifolia(Bertol.) Kuntze & 1 & 1 & 0 \\
\hline Pitaia/Pitaia-branca & Hylocereus undatus(Haw.) Britton \& Rose & 0 & 1 & 2 \\
\hline Quiabo de Metro & Trichosanthes cucumerinaL. & 2 & 2 & 0 \\
\hline Radite & Hypochaeris cbillensis(Kunth) Britton & 3 & 2 & 0 \\
\hline Serralha & Sonchus oleraceusL. & 4 & 5 & $I^{*}$ \\
\hline Taioba & Xanthosoma taioba E.G. Gonç. & 5 & 5 & 5 \\
\hline Tanchagem & Plantago australisLam. & 14 & 6 & $I^{*}$ \\
\hline Tanchagem-grande & Plantago major $\mathrm{L}$. & 9 & 3 & $\mathrm{I}^{*}$ \\
\hline Bálsamo & Cotyledon orbiculata & 20 & 6 & 2 \\
\hline
\end{tabular}

Fonte: Resultados da pesquisa elaborados pelos autores. Birigui (SP), julho de 2018. I* = incontável 
Tabela 2.Descrição de plantas medicinais e suas quantidades encontradas nas hortas comunitárias de Birigui/SP

\begin{tabular}{|c|c|c|c|c|}
\hline Nome popular & Nome científico & $\begin{array}{c}\text { Canteiros } \\
\text { (n) }\end{array}$ & $\begin{array}{l}\text { Hortas } \\
\text { (n) }\end{array}$ & $\begin{array}{c}\text { Fora dos } \\
\text { canteiros } \\
\text { (n) }\end{array}$ \\
\hline Alcanfor & Cinnamomum camphora & 2 & 1 & 0 \\
\hline Alfavaca & Ocimum capechianum Mill & 14 & 5 & 1 \\
\hline Alecrim & Rosmarinus officinalis & 120 & 24 & 9 \\
\hline Arruda & Ruta graveolens & 91 & 25 & $I^{*}$ \\
\hline Babosa & Aloe Vera & 27 & 17 & 21 \\
\hline Bálsamo & Cotyledon orbiculata & 20 & 6 & 2 \\
\hline Boldo & Peumus boldus & 0 & 22 & 49 \\
\hline Camomila & Matricaria chamomilla & 22 & 7 & 2 \\
\hline Capim Limão/Erva Cidreira & Cymbopogon citratus (DC.) Stapf & 64 & 28 & 36 \\
\hline Cártamo & Carthamus tinctorius $L$. & 1 & 1 & 0 \\
\hline Carqueija & Baccharis articulata (Lam.) Pers. & 22 & 11 & 0 \\
\hline Cavalinha & Equisetum & 1 & 1 & 0 \\
\hline Citronela & Cymbopogon & 2 & 3 & $\mathrm{I}^{*}$ \\
\hline Confrei & Symphytum officinale & 15 & 9 & 0 \\
\hline Dente de leão & Taraxacum officinale F.H. Wigg. & 6 & 4 & 2 \\
\hline Erva Cidreira/Melissa & Melissa officinalis & 31 & 13 & $\mathrm{I}^{*}$ \\
\hline Erva-de-Santa-Maria/Mastruz & Chenopodium ambrosioides $L$. & 98 & 29 & 24 \\
\hline Funcho/Erva-doce/Falsa-erva-doce & Foeniculum vulgare Mill. & 9 & 6 & $I^{*}$ \\
\hline Gengibre & Zingiber officinale & 29 & 11 & 1 \\
\hline Guaco & Mikania glomerata Spreng & 13 & 11 & 9 \\
\hline Hibisco & Hibiscus sabdariffa $L$ & 2 & 2 & 0 \\
\hline Hortelã Pimenta & Plectranthus amboinicus (Lour.) Spreng. & 9 & 5 & 0 \\
\hline Hortelã Verde & Mentha spicata & 141 & 26 & $\mathrm{I}^{*}$ \\
\hline Levante & Mentha spicata L. & 6 & 4 & $\mathrm{I}^{*}$ \\
\hline Losna & Artemisia absinthium & 25 & 18 & 4 \\
\hline Malva & Malva sylvestris $L$. & 0 & 4 & 5 \\
\hline Manjericão & Ocimum basilicum & 58 & 17 & $\mathrm{I}^{*}$ \\
\hline Marcela & Achyrocline satureioides & 4 & 2 & 0 \\
\hline Mentruz & Coronopus didymus (L.) Sm. & 15 & 7 & 6 \\
\hline Melão-de-São-Caetano & Momordica charantia L. "Goya" & 2 & 2 & 0 \\
\hline Noni & Morinda citrifolia $L$. & 5 & 6 & 1 \\
\hline Novalgina & Acbillea Millefolium & 3 & 2 & 0 \\
\hline Óregano & Origanum vulgare & 28 & 14 & 0 \\
\hline Penicilina & Alternanthera brasiliana (L.) Kuntze var. brasiliana. & 1 & 1 & 0 \\
\hline Poejo & Mentha pulegium & 18 & 16 & 9 \\
\hline Quebra Pedra & Pbyllanthus niruri & 0 & 6 & 13 \\
\hline Rubim & Leonurus sibiricus & 3 & 1 & 0 \\
\hline Sete-sangrias & Cuphea carthagenensis & 1 & 1 & 0 \\
\hline Tanchagem & Plantago australis Lam. & 14 & 6 & $\mathrm{I}^{*}$ \\
\hline Tanchagem-grande & Plantago major $L$ & 9 & 3 & $\mathrm{I}^{*}$ \\
\hline Vick & Mentha arvensis L. var. Piperascens Holmes & 2 & 2 & 0 \\
\hline Romã & Punica granatum & 5 & 2 & 5 \\
\hline Insulina & Cissus verticillata & 1 & 1 & 0 \\
\hline Arnica & Porophyllum ruderale(Jacq.) Cass. & 11 & 6 & $\mathrm{I}^{*}$ \\
\hline
\end{tabular}

Identificou-se grande comercialização em apenas duas hortas comunitárias $(6,7 \%)$, fator que vai contra a proposta do projeto "Hortas comunitárias". Essa grande comercialização deve-se a indivíduos que utilizam os seus canteiros como forma de renda familiar, comercializando em algumas vendas de bairros, verdureiros ambulantes e alguns minimercados. Os dados podem ser observados no Gráfico 1.

Todas as visitas realizadas foram importantes para agregar conhecimento e entender como cada canteiro possui valor significativo na vida dos horticultores de cada comunidade. Pode-se observar 
que a maioria dos beneficiários são idosos e encontram nas hortas não apenas um meio de produção de hortaliças para consumo, mas sim uma forma de terapia, um refúgio da vida industrial e uma maneira de amenizar todo o cansaço físico e mental que a rotina nas grandes cidades possa a vir oferecer, principalmente após a aposentadoria[7].

Durante a conversa com o guia e busca pelas plantas nas visitas houve menção ao termo PANC. Muitos se mostraram sem conhecimento acerca do assunto, porém com manifestação expressiva de interesse e questionamentos às pesquisadoras, situação que gerou uma intensa troca de conhecimentos.

Durante essas conversas, ao expor alguns exemplos de PANC mais comuns na região, foi detectado o conhecimento de algumas advindos da influência de pais e avós, visto que a maioria dos horticultores são oriundos da zona rural, somada a idade mais avançada e o consumo já frequente de algumas espécies vegetais sem o conhecimento da denominação PANC, do valor nutricional, funcionalidade no organismo, e até modo de preparo adequado ${ }^{[8]}$.

Ademais, pode-se notar que algumas plantas identificadas são confundidas com pragas ou ervas daninhas, ou seja, plantas que prejudicam o crescimento das hortaliças convencionais, sendo descartadas. Nesta troca informal de conhecimento, notou-sea surpresa dos guias quando informações sobre valor nutricional e outros benefícios eram informados.

Gráfico 1. Comercialização de hortaliças em Hortas Comunitárias do município de Birigui*

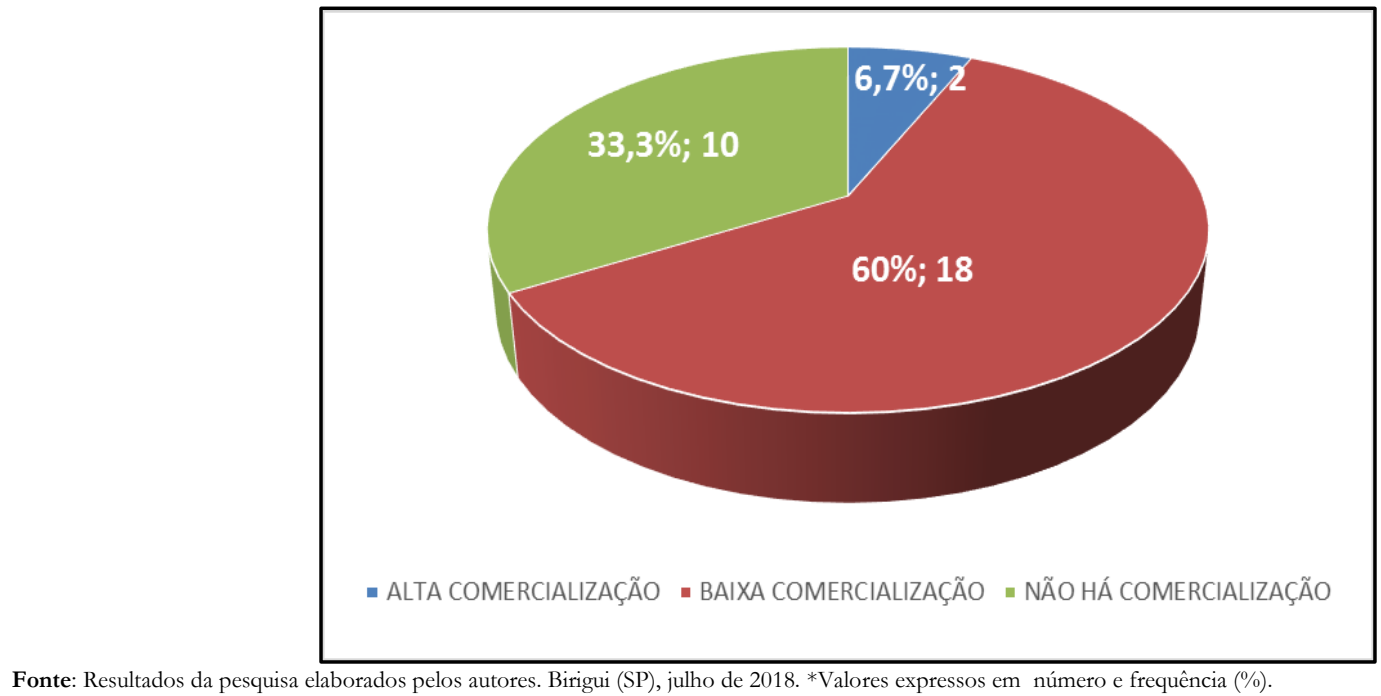


Gráfico 2. Uso de agrotóxicos nas hortas comunitárias do município de Birigui - SP

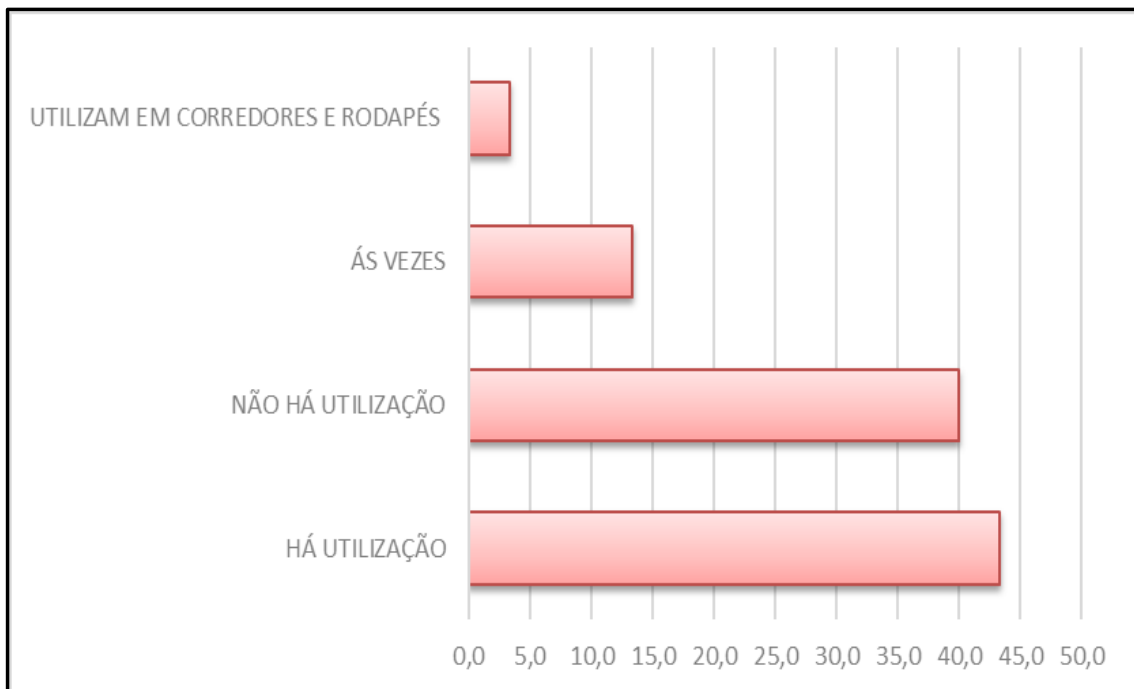

Fonte: Resultados da pesquisa elaborados pelos autores. Birigui (SP), julho de 2018

Hanke, Biesek, Winck e Silva[7] obtiveram em sua pesquisa resultados mostrando que a população estudada conhece e utiliza as PANC, porém desconhece essa dominação, bem como as partes que podem ser utilizadas, modo de preparo e valor nutricional. Ressalta-se que este não foi o objetivo do trabalho e, portanto, não houve coleta e análise desses dados que são descritos aqui devido a relevância e construção de conhecimento por ambas as partes durante a realização das visitas. Sugere-se, ainda, que o tema seja investigado a fundo com os horticultores para que trabalhos de educação alimentar e nutricional possam ser realizados.

Segundo Paschoal, Gouveia e Souza[9], esse é um tema que vem crescendo. Os autores reconhecem valores ambientais, nutricionais e sociais que devem ser aprofundadom, principalmente, em relação aos fatores antinutricionais das PANC.

Pode-se chamar de plantas medicinais aquelas que possuem características que auxiliam no tratamento de doenças ou melhoram as condições de saúde das pessoas. Desde épocas remotas, o homem possui conhecimento sobre diversas espécies de plantas que possuem propriedades medicinais, porém, com o avanço da civilização e dificuldades para a obtenção de princípios ativos nas concentrações devidas, os fármacos sintéticos ganharam espaço no mercado facilitando o acesso aos tratamentos patológicos. No entanto, as plantas medicinais seguem como alternativa de tratamento ${ }^{[10,11]}$.

Segundo Badke, Somavilla, Heisler, de Andrade, Budó e Galert ${ }^{[11]}$, o conhecimento dos horticultores acerca das plantas medicinais está diretamente relacionado aos saberes herdado da família, principalmente pais e avós, e a vivência em propriedades rurais durante certo período da vida.

Dentre as plantas identificadas, as mais encontradas foram: Erva-de-santa-Maria (Chenopodiumambrosioides L), Capim-limão (Cymbopogoncitratus (DC.) Stapf), Arruda (Rutagraveolens), Alecrim (Rosmarinusofficinalis), e Hortelã (Menthaspicata). Segundo o Memento Fitoterápico, a Erva-de-santaMaria e o Capim-limão estão classificadas como plantas medicinais ${ }^{[12]}$, e também como PANC devido espontaneidade no crescimento e propagação sem grandes cuidados ${ }^{[4]}$.

\section{A Erva-de-santa-Maria (Chenopodium} ambrosioides L) apresenta efeitos positivos no tratamento de endoparasitoses em seres humanos e animais, porém é necessária maior atenção em sua posologia, visando a diminuir os efeitos colaterais e aproveitando ao máximo seus benefícios ${ }^{[13]}$. 
O Capim-limão (Cymbopogon citratus (DC.) Stapf) também conhecido como capim santo, capim cheiroso, capim-cidreira, entre outros, é uma planta que tem se mostrado bastante eficaz no tratamento de doenças como hipertensão arterial, dores de cabeça por seu efeito analgésico, além de seu efeito calmante e anti-espasmolitica. É bastante utilizada na forma de chás e na forma de óleo essencial[14].

Conhecida popularmente como planta protetora, a Arruda (Ruta graveolens) tem, além de suas folhas, suas flores e raízes como parte utilizada, atuante no tratamento de varizes e como emenagogo, por seu efeito sobre a resistência nos vasos sanguíneos, possui efeitos benéficos sobre as complicações causadas no período menstrual. Auxilia no tratamento de dores reumáticas, dores de cabeça, úlceras e tratamento de cistos. Essa planta medicinal apresenta efeitos no tratamento como um analgésico, antiinflamatório, calmante, febrífuga, vermífuga e fortificante, trazendo muitos benefícios sendo um tratamento natural muito utilizada em amplas variedades de doenças ${ }^{[15,16]}$.

Com características aromáticas, o Alecrim (Rosmarinusofficinalis) tem um valor medicinal muito grande, utilizada no tratamento de dores de cabeça, doenças da circulação, epilepsia entre outras, devido suas funções antioxidante e antimicrobiana ${ }^{[17]}$.

Da família Lamiaceae a Hortelã (Menthaspicata) possui diversas variedades, com forte utilização na culinária, como planta medicinal preparada em infusão e óleo essencial, com efeito sobre o trato gastrointestinal, ação anti-helmíntica, antisséptico bucal e efeito calmante. É uma planta medicinal, com propriedades expectorantes, vermífuga, colagoga, antisséptica, antiespasmódica, entre outros benefícios. A hortelã é utilizada também como remédios para dores musculares. Além disso, é rica em vitaminas A e C e minerais como ferro, cálcio, fósforo e potássio, com propriedades antioxidantes ${ }^{[18,19]}$.

As plantas medicinais e PANC, encontradas nos canteiros das hortas comunitárias, possuem importante papel como alimentos e em processos patológicos, conforme pode ser observado com a descrição supracitada das principais, encontradas nos locais visitados. Identificar essas plantas foi um passo importante para que, a partir disso, atividades de informação e uso correto possam ser disseminadas.
Constatou-se que muitas práticas rotineiras dos utilizadores dos canteiros vão contra o projeto inicial das hortas comunitárias, principalmente nos quesitos comercialização e utilização de compostos químicos. Deve-se salientar, também, que o projeto é de 1994[6] e está sendo revisado pelas autoridades responsáveis.

De acordo com a Lei Brasileira no 7.802, de 11 de julho de 1989, artigo 2o[20], consideram-se:

I - Agrotóxicos e afins:

a) os produtos e os agentes de processos físicos, químicos ou biológicos, (...) cuja finalidade seja alterar a composição da flora ou da fauna, a fim de preserválas da ação danosa de seres vivos considerados nocivos;

b) substâncias e produtos, empregados como desfolhantes, dessecantes, estimuladores e inibidores de crescimento.

Sobre o uso de agrotóxicos, encontrou-se aplicação em alguns canteiros, mesmo esta prática sendo irregular conforme o projeto municipal que rege as hortas $\left[{ }^{[0]}\right.$.

Durante as visitas notou-se, a sua utilização, em épocas específicas do ano, em plantações anteriores e ao redor dos canteiros. Todavia, sabe-se que estes produtos deixam resquícios químicos no solo e acabam contaminando as cultivares num raio de 500 metros, por meio do solo, água e ar [21,22]. A falta de conhecimento sobre essa propagação pode ser responsável por esta prática em corredores e rodapés dos canteiros, afinal não se tem a ciência de que estão expostos a condições de doença, tornando-se, assim, fundamental a conscientização e ensino de práticas de controle de pragas que sejam ecológicas e sustentáveis.

A alta exposição humana a esses compostos químicos, acrescida ao desconhecimento sobre os riscos, forma de manejo, normas de segurança, fácil acesso e a falta de fiscalização têm sido fator chave para o uso indiscriminado destes compostos químicos e relaciona-se a exposição humana a estes produtos ao desenvolvimento de doenças agudas e crônicas, o que constitui um grave problema para a saúde pública[21,23]. 
Sobre a comercialização das hortaliças cultivadas nas hortas comunitárias, considerando o atual projeto municipal, é descrito a proibição deste ato[ []. No entanto, outra realidade foi encontrada e, em alguns locais, de forma a não angariar lucros, ou seja, vende-se apenas em pequenas quantidades e por valores simbólicos, de modo que possam retirar desta pequena comercialização os gastos com adubos, mudas e outros, que não foram subsidiados pelo poder público, além da presença de doações do excedente cultivado.

\section{CONCLUSÃO}

Foi verificada nas hortas comunitárias frequência elevada da presença de PANC e de plantas medicinais, sendo algumas cultivadas e outras de aparecimento espontâneo e tratadas como ervas daninhas por falta de conhecimento da população envolvida. Sugere-se ações locais de resgate cultural e alimentar acerca dessas plantas.

A utilização de agrotóxicos e comercialização das cultivares são praticas não aceitas no projeto inicial das "Hortas Comunitárias", mas que ocorrem com pouca frequência ou de forma a subsidiar custos. Ações de educação ambiental podem ser promovidas para conscientizar e informar os horticultores sobre o uso de produtos químicos nos corredores, rodapés e canteiros.

A respeito da comercialização dos produtos sugere-se ações de informação ou que novas regras sejam incorporadas ao projeto, que vem sendo reformulado, a fim de que valores simbólicos e/ou doações possam ser estimuladas para garantir que o excedente de produção possa chegar a famílias com menor poder aquisitivo e assegurar, dessa forma, o consumo de produtose innatura, com menor ou nenhum teor de resíduo químico.

Ademais, o projeto e suas possíveis melhorias são uma ação importante com vista a garantir a soberania alimentar e o Direito Humano a Alimentação Adequada condicionando a melhor qualidade de vida e possibilidade de acesso a alimentos para as familias e comunidade local.

\section{AGRADECIMENTOS}

Expressamos aqui nosso agradecimento a todos os funcionários da Secretaria de Meio Ambiente e Desenvolvimento Social que nos auxiliaram na execução desta pesquisa disponibilizando endereço e no reconhecimento das plantas, em especial Ronaldo Caramujo e Jeferson Rabal. Nosso agradecimento estende-se a Adão Donizete Panini que pela sua vivência e conhecimento das áreas de agroecologia e agricultura viabilizou a identificação das plantas.

\section{REFERÊNCIAS}

[1] Brasil. Ministério do Desenvolvimento Social e Combate à Fome. Santandreu A, Lovo IC. Panorama da agricultura urbana e periurbana no Brasil e diretrizes políticas para sua promoção. Rede de Intercâmbio de Tecnologias Alternativas. Brasília: MDS [Internet] 2007 [acesso em 07 mai 2018];12(4). Disponível em: http://www.agriculturaurbana.org.br

[2] Branco MC, Alcântara FA. Hortas urbanas e periurbanas: o que nos diz a literatura brasileira? Rev Hortic Bras [Internet] 2011 [acesso em 07 mai 2018];29(3). Disponível em:http://www.scielo.br/scielo.php?script=sci_arttext\&pid=S 0102-05362011000300028

[3] Brasil. EMBRAPA. Machado AT, Machado CT'T. Agricultura Urbana: Embrapa Cerrados. Planaltina: Embrapa [Internet] 2002 [citado em 07 mai 2018]. Disponível em: https://ainfo.cnptia.embrapa.br/digital/bitstream/CPAC2009/22469/1/doc_48.pdf

[4] Lorenzi H, Kinupp VF. Plantas alimentícias não convencionais (PANC) no Brasil. São Paulo: Plantarum; 2014.

[5] Almeida MEF, Corrêa AD. Utilização de cactáceas do gênero Pereskia na alimentação humana em um município de Minas Gerais. Rev Ciência Rural [Internet] 2012 [acesso em 07 mai 2018];42(4). Disponível em: http://www.scielo.br/pdf/cr/v42n4/a11112cr5075

[6] Prefeitura Municipal de Birigui. Projeto de Lei Municipal Hortas Comunitárias de Birigui/SP. 1994.

[7] Hanke D, Biesek MF, Wink BR, Da Silva RW. Hortas urbanas Agroecológicas sob linhas de transmissão de energia e o fortalecimento de organizações sociais na região Sul do município de Curitiba - PR. In: Anais do I Simpósio laboratório de estudos de ciência, tecnologia e sociedade [nternet]; 2011; São Carlos. São Carlos: Universidade de São Carlos; 2011 [acesso em 30 ago 2018]. Disponível em: http://www.esocite.org.br/eventos/tecsoc2011/cdanais/arquivos/pdfs/artigos/gt013-hortasurbanas.pdf 
[8] Balbinot S, Velasquez PG, Dusman E. Reconhecimento e uso de plantas medicinais pelos idosos do Município de Marmeleiro - Paraná. Rev Bras Pl Med [Internet] 2013 [acesso em 24 out 2018];15(4):632-638. Disponível em: http://www.scielo.br/pdf/rbpm/v15n4s1/02.pdf

[9] Paschoal V, Gouveia I, Dos Santos Souza N. Plantas Alimentícias Não Convencionais (PANCs): o potencial da biodiversidade brasileira. Rev Bras de Nutr Funcional [Internet] 2016 [acesso em 04 set 2018];16(68):8-14. Disponível em: https://www.vponline.com.br

[10] Badke RM, Budó MLD, Alvim NAT, Zanetti GD, Heisler EV. Saberes e práticas populares de cuidado em saúde com o uso de plantas medicinais. Rev Text Contex Enferm [Internet] 2012 [acesso em 07 set 2018];21(2):363-370. Disponível em: http://www.scielo.br

[11] Badke MR, Somavilla CA, Heisler EV, De Andrade V, Budó MLD, Garlet TMB. Saber popular: uso de plantas medicinais como forma terapêutica no cuidado à saúde. Rev Enferm UFSM [Internet] 2016 [acesso em 07 set 2018];6(2):225-234. Disponível em: https://periodicos.ufsm.br

[12] Brasil. ANVISA. Memento Fitoterápico - Farmacopeia Brasileira. Brasília: Agência Nacional de Vigilância Sanitária (ANVISA);2016.

[13] Pozzatti PN, Casagrande FP, Valentim TP, Gai ZT, Porfírio LC. Aspectos farmacológicos e terapêuticos da utilização de Erva-de-santa-maria (Chenopodium ambrosioides) em humanos e animais. Rev Pubvet [Internet] 2010 [acesso em 10 set 2018];4(35). Disponível em: http://www.pubvet.com.br/uploads/9697374ad1d62743e38ab e4b0a0fc324.pdf

[14] Pereira PS, De Paula LLRJ. Ações terapêuticas do capimsanto: uma revisão de literatura. Rev Saúde em Foco [Internet] 2018 [acesso em 10 set 2018];10:259-263. Disponível em:http://unifia.edu.br/revista_eletronica

[15] Neto AR, Pinto MA, Silva IR, Moraes SC, Gomes ML. Atividades farmacológicas da Arruda (Ruta graveolens). In: Anais do VIII Congresso de Ecologia do Brasil [Internet]; 2007; Caxambu. Caxambu: VIII Congresso de Ecologia do Brasil; 2007 [acesso em 16 set 2018]. Disponível em: http://www.sebecologia.org.br/viiiceb/pdf/577.pdf

[16] Ratheesh M, Helen A. Anti-inflammatory activity of Ruta graveolens Linn on carrageenan induced paw edema in wistar male rats. Academic Journals Short Communication [Internet] 2007 [acesso em 16 set 2018];6(10):1209-1212. Disponível em: https://www.ajol.info/index.php/ajb/article

[17] Santos CDP, De Souza BHS, De Almeida LM, Custódio LB. Efeitos do Alecrim (Rosmarinus officinalis) na saúde humana: uma revisão de literatura. In: Anais doII Congresso Brasileiro de Ciências da Saúde [Internet]; 2017; Campina Grande. Campina Grande: II Congresso Brasileiro de Ciências da Saúde; 2017 [acesso em 16 set 2018]. Disponível em: http://editorarealize.com.br

[18] Júnior HPL, De Lemos ALA. Hortelã. Rev Nutrolog Diagn Tratamen [Internet] 2012 [acesso em 16 set 2018];17(3):115-117. Disponível em: http:// files.bvs.br/upload/S/1413-9979/2012/v17n3/a3102

[19] Radünz LL, De Castro Melo E, De Almeida Barbosa LC, Santos RHS, Da Fonseca Barbosa F, Martinazzo AP. Influência da temperatura do ar de secagem no rendimento do óleo essencial da hortelã comum Mentha x Villosa huds).. Rev Eng na Agricul. [Internet] 2006 [acesso em 16 set 2018]. Disponível em: https://periodicos.ufv.br/reveng

[20] Brasil. Lei no 7.802, de 11 de julho de 1989. Dispõe sobre a pesquisa, a experimentação, a produção, a embalagem e rotulagem, o transporte, o armazenamento, a comercialização, a propaganda comercial, a utilização, a importação, a exportação, o destino final dos resíduos e embalagens, o registro, a classificação, o controle, a inspeção e a fiscalização de agrotóxicos, seus componentes e afins, e dá outras providências [nternet] 1989 [acesso em 9 set 2018]; Disponível em: http://www.planalto.gov.br

[21] Siqueira DF, Moura RM, Carneiro GE, Laurentino, De Araújo AJ, Cruz SL. Analise da exposição de trabalhadores rurais a agrotóxicos. Rev Bras Promoc Saude [Internet] 2013 [acesso em 16 set 2018];26(2):182-191. Disponível em: http://www.redalyc.org/pdf/408/40828920005.pdf

[22] Brasil. Associação Brasileira de Saúde Coletiva. Augusto LGS, Carneiro FF, Pignati W, Rigotto RM, Friedrich K, Faria NMX, Búrigo AC, Freitas VMT, Guiducci Filho E. Dossiê ABRASCO - um alerta sobre os impactos dos agrotóxicos na saúde. Parte 2 - Agrotóxicos, Saúde, Ambiente e Sustentabilidade. Rio de Janeiro: ABRASCO [Internet] 2012 [acesso em 15 out 2018]. Disponível em: https://www.abrasco.org.br

[23] De Lima Tejerina GR. Intoxicações e óbitos por agrotóxicos no Estado de Goiás, Brasil e inovações legislativas. Rev Cad Ibero-Amer Dir Sanit [Internet] 2018 [acesso em 16 set 2018];7(1):229-249. Disponível em: http://pesquisa.bvsalud.org/portal/resource/pt/biblio-882303 